\title{
Crystal growth and characterization of Cu-based multinary compound semiconductors $\mathrm{Cu}$ ベース多元化合物半導体の結晶成長と評価
}

\author{
Takashi MAEDA, Keisuke SHIMIZU, Shin'ichiro AI, Hiroaki MATSUSHITA and Akinori KATSUI \\ Department of Material Science and Technology, School of High-Technology for Human Welfare, Tokai Univ. \\ 317 Nishino, Numazu, Shizuoka, 410-03 JAPAN \\ Tel: 81-559-68-1211(ext.4406), FAX: 81-559-68-1155 \\ ( Accepted for publication 6 November 1997 ) \\ Among $\mathrm{Cu}$-based multinary compounds, we have attempted to grow $\mathrm{Cu}_{2}-\mathrm{IV}-\mathrm{Se}_{3}$ and $\mathrm{Cu}-\mathrm{III}-\mathrm{IV}-\mathrm{Se}_{4}$ compounds (III \\ $=\mathrm{Ga}, \mathrm{In} ; \mathrm{IV}=\mathrm{Ge}, \mathrm{Sn}$ ). It is found that $\mathrm{Cu}_{2} \mathrm{GeSe}_{3}, \mathrm{Cu}_{2} \mathrm{SnSe}_{3}, \mathrm{CuGaGeSe}_{4}$ and Se-rich CulnGeSe $\mathrm{Cu}_{4}$ are formed a single \\ phase by melt growth, and these lattice constants are determined from powder X-ray diffraction. From the \\ temperature dependence of electrical resistivities, thermal band gaps of $\mathrm{Cu}_{2} \mathrm{SnSe}_{3}$ and $\mathrm{CuGaGeSe}_{4}$ are estimated to \\ be 0.44 and $0.46 \mathrm{eV}$, respectively.
}

Keyword: Cu-based compound, single phase, crystal growth, band gap

\section{INTRODUCTION}

現在、発電用太陽電池としては、Si系(単結晶 およびキャストのバルク型)のものが中心に実用 化され、普及している。また、アモルファスSi系、 II-VI族化合物 (Cd'Te) 系などの薄膜太陽電池材料 をはじめ、様々な材料の研究・開発が進んでいる。 しかし、大規模に実用化を進めるためには、変換 効率、コスト、材料供給、量産技術など、様々な 課題がある。これらの問題点を克服するために、

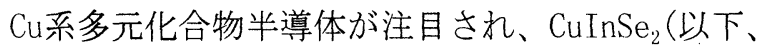
CIS 略称する) 系などを中心に研究が盛んに行わ れており、変換効率も17\%以上と飛躍的に上がっ てきている。

Cu系多元化合物半導体の利点として、以下の ような点を挙げることができる。第一に材料が比 較的安価に、かつ安定して供給することができる。 第二に直接遷移型で、Si系など間接遷移型のもの に比べて光素子に有効である。第三に吸収係数が 大きいため、数 $\mu \mathrm{m}$ 厚さでも十分太陽光スペクト ルを吸収することができる。本研究では、CIS系 に次ぐ新しいCu系多元化合物半導体の光活性層材 料として、 $\mathrm{Cu}_{2}-\mathrm{IV}-\mathrm{VI}_{3} 、 \mathrm{Cu}-\mathrm{III}-\mathrm{IV}-\mathrm{VI}_{4}$ に着目し、 バルク特性の測定・系統的分類を行う。

\section{EXPERIMENTAL PROCEDURE}

最初に示差熱分析により得られた反応温度、
融点などを検討し、横型簡易炉を用いて二元化合 物などの混合物から単相試料の作製を試みた。粉 末X線回折測定で作製した試料の相を同定し、単 相の試料において結晶系の決定、面指数付け、格 子定数の計算を行った。単相作製法が確認された 物質に関して、ブリッジマン法を用いて単結晶成 長を行った。これらの単結晶において、光透過率、 抵抗率、ホール効果測定を用いて評価した。これ らの結果より、バンドギャップなどの物性定数を 求め、光活性層材料としての検討・分類を行った。

\section{RESULTS}

$\mathrm{Cu}_{2} \mathrm{SnSe}_{3} 、 \mathrm{Cu}_{2} \mathrm{GeSe}_{3} 、 \mathrm{CuGaGeSe}_{4}$ 、 $\mathrm{CuGaSnSe}_{4} 、 \mathrm{CuInGeSe}_{4} 、 \mathrm{CuInSnSe}_{4}$ 関して、 それぞれの単相作製法の検討を行い、実際に作製 した試料のX線回折パターン(Fig. 1)から、 $\mathrm{Cu}_{2} \mathrm{GeSe}_{3} 、 \mathrm{Cu}_{2} \mathrm{SnSe}_{3} 、 \mathrm{CuGaGeSe}_{4}$ は単相であ ると同定された。CuInGeSe 4 はSeを過剩にした 試料において、単相形成が可能であることがわ かった。また $\mathrm{Cu}_{2} \mathrm{SnSe}_{3}$ は立方晶系で、そのほか は正方晶系であり、図中(Fig. 1)に示すように、 格子定数を決定できた。 $\mathrm{CuGaSnSe}_{4}$ 、 CuInSnSe 4 は、まだ単相形成することはできず、 現在作製法の検討を行っている。

次に、単相が形成できたものに関しては、単 結晶成長を試みた。その結果、 $\mathrm{Cu}_{2} \mathrm{SnSe}_{3}$ (縦型ブ リッジマン法)、 $\mathrm{CuGaGeSe}_{4}$ (横型ブリッジマン 
法)は単結晶の成長を行うことができた。しかし、 $\mathrm{Cu}_{2} \mathrm{GeSe}_{3} 、 \mathrm{CuInGeSe} \mathrm{Cl}_{4}$ 関してはマイクロク ラックが多く、多結晶の状態であった。これらは、 結晶作製条件(温度勾配、成長速度など)の再検討 が必要である。

$\mathrm{Cu}_{2} \mathrm{SnSe}_{3} 、 \mathrm{CuGaGeSe}_{4}$ 単結晶試料で光透過率 測定、抵抗率及びホール効果測定を行った。 $\mathrm{Cu}_{2} \mathrm{SnSe}_{3} 、 \mathrm{CuGaGeSe}_{4}$ に関しては、2500 nmよ り短波長の光を照射しても透過が見られなかった ことから、バンドギャップは $0.5 \mathrm{eV}$ 以下であると 考えられる。

また、これらの物質の抵抗率の温度依存につ いてFig. 2に示寸。真性領域での抵抗率の温度依 存性より求めたバンドギャップは、 $\mathrm{Cu}_{2} \mathrm{SnSe}_{3}$ が $0.44 \mathrm{eV} 、 \mathrm{CuGaGeSe}_{4}$ が $0.46 \mathrm{eV}$ であり、光透過 率測定の結果と一致していた。

\section{SUMMARY}

本研究で得られた物性定数をTABLE 1に示寸。 $\mathrm{Cu}_{2} \mathrm{SnSe}_{3} 、 \mathrm{Cu}_{2} \mathrm{GeSe}_{3}$ (報告值: $\left.\mathrm{Eg} \sim 0.25 \mathrm{eV}\right)^{1}$ は、 バンドギャップが太陽電池材料としては小さすぎ るので、VI族をSeからSに置換するなどして、バ ンドギャップを広げる必要がある。 $\mathrm{CuGaGeSe}_{4}$ は、かつて報告されている值 $(\mathrm{Eg} \sim 1.35 \mathrm{eV})^{2}$ より バンドギヤップが小さく、この不一致については、 今後再検討寸べきであろう。

\section{REFERENCES}

${ }^{1}$ S. Endo, I.Sudo and T.Irie, Jpn. J. Appl. phys. 10 (1971) 218.

${ }^{2}$ D. K. Ghosh, P.S.Ghost and L.K.Samanta, Phys. Rev. B 41 (1990) 5126.

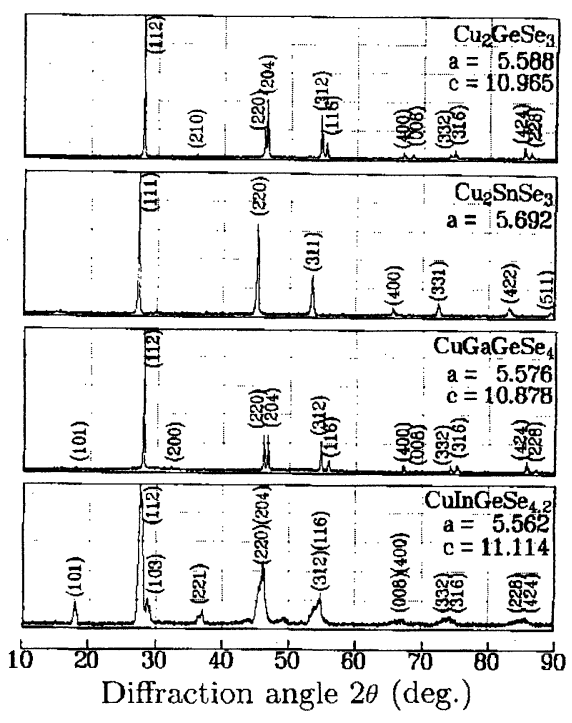

FIG. 1. X-ray diffraction patterns of $\mathrm{Cu}_{2}$-IV-Ses and $\mathrm{Cu}$-III-IV-Se ${ }_{4}$ compounds.

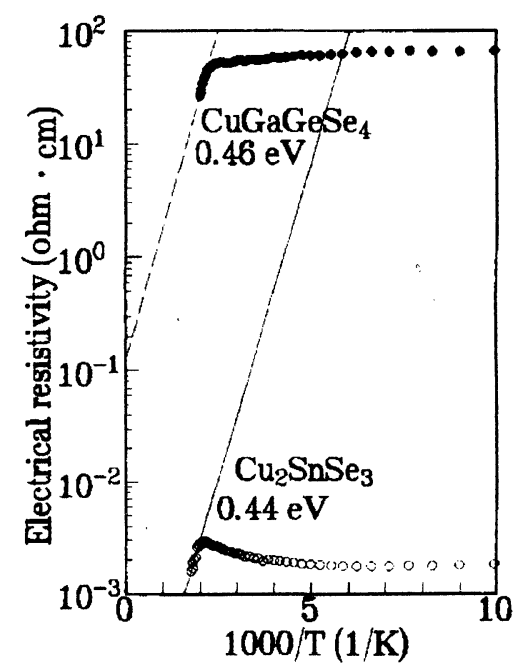

FIG. 2. Temperature dependence of electrical resistivities of $\mathrm{Cu}_{2} \mathrm{SnSe}_{3}$ and $\mathrm{CuGaGeSe}_{4}$ compounds.

TABLE. 1 Some physical properties of $\mathrm{Cu}_{2}$-IV-Se 3 and $\mathrm{Cu}$-III-IV-Se 4 compounds

\begin{tabular}{|c|c|c|c|c|c|c|c|}
\hline Compounds & $\begin{array}{c}\text { Melting } \\
\text { Point }\left({ }^{\circ} \mathrm{C}\right)\end{array}$ & $\begin{array}{l}\text { Crystal } \\
\text { System }\end{array}$ & $\begin{array}{r}\text { Lat } \\
\text { Consta } \\
\mathrm{a}\end{array}$ & $\begin{array}{l}\text { tice } \\
\text { ints }(\AA) \\
\text { c }\end{array}$ & $\begin{array}{c}\text { Conduction } \\
\text { Type }\end{array}$ & $\begin{array}{c}\text { Resistivity } \\
\text { at R.T. } \\
(\Omega \mathrm{cm})\end{array}$ & $\begin{array}{c}\text { Thermal Gap } \\
(\mathrm{eV})\end{array}$ \\
\hline $\mathrm{Cu}_{2} \mathrm{SnSe}_{3}$ & 695 & Cubic & 5.692 & - & $\mathrm{p}$ & $\sim 10^{-3}$ & 0.44 \\
\hline $\mathrm{Cu}_{2} \mathrm{GeSe}_{3}$ & 768 & Tetragonal & 5.588 & 10.965 & $p$ & $10^{-2} \sim 10^{-1}$ & - \\
\hline $\mathrm{CuGaGeSe}_{4}$ & 836 & Tetragonal & 5.576 & 10.878 & $\mathrm{p}$ & $10^{1} \sim 10^{3}$ & 0.46 \\
\hline $\mathrm{CuGaSnSe}_{4}$ & - & - & - & - & - & - & - \\
\hline $\mathrm{CuInGeSe}_{4}$ & $810^{*}$ & Tetragonal & $5.562^{*}$ & $11.114^{*}$ & $\mathrm{p}$ & - & - \\
\hline $\mathrm{CuInSnSe}_{4}$ & - & - & - & - & - & - & - \\
\hline
\end{tabular}

*values of $\mathrm{CuInGeSe} 4.2$

'97 SAS Intelligent Symposium 